\title{
Evaluation of the Psychological Status in Chronic Low Back Pain: Comparison with General Population
}

\author{
Laxmaiah Manchikanti, MD*, Vidyasagar Pampati, MSc**, Carla Beyer, RN"\#, Kim Damron, RN"\#, \\ and Renee C. Barnhill, RN"\#
}

Multiple studies have documented a strong association between chronic low back pain and psychopathology including personality disorders, depressive disorders, anxiety, and somatoform disorders along with non-specific issues such as emotion, anger and drug dependency. However, depression, anxiety and somatization appear to be crucial. There are no controlled trials in interventional pain management settings.

This study was designed to evaluate 40 individuals without pain or psychotherapeutic drug therapy, Group I, control group; and Group II, chronic low back pain group with 40 chronic low back pain patients. All the participants were tested utilizing Pain Patient Profile (P3).

The importance of psychological and social factors in understanding chronic low back pain is widely recognized. Chronic low back pain now is viewed as a biopsychosocial phenomenon, in which biological, psychological, and social factors dynamically interact with one another (1). With continued exploration of psychological factors in chronic low back pain, and explosion of literature psychopathology is diagnosed in chronic low back pain with increasing frequency. Research on psychopathology in chronic low back pain documented increased prevalence of depression, anxiety, substance abuse or dependence, somatization, and personality disorders compared with general population (1-19). High rates of psychiatric disorders have also been found to be associated with headaches, temporomandibular disorders, pelvic pain and fibromyalgia along with, chronic medical conditions $(1,3)$.

It has been described that unrecognized and untreated psy-

From Pain Management Center of Paducah, Paducah, Kentucky. *Medical Director, **statistician, and ${ }^{* \#}$ clinical coordinators at the Pain Management Center of Paducah. Address correspondence: Laxmaiah Manchikanti, MD, 2831 Lone Oak Road, Paducah, Kentucky 42003. E-mail: drm@apex.net
Significant differences were found among various clinical syndromes with generalized anxiety disorder, somatoform disorder, and depression, with $0 \%$ vs $20 \%, 0 \%$ vs $20 \%$, and $5 \%$ vs $30 \%$ in Group I and Group II consecutively.

This evaluation showed that clinical syndromes were seen in a greater proportion of patients with chronic low back pain emphasizing the importance of evaluation of the patients for generalized anxiety disorder, somatoform disorder, and for depression.

Keywords: Chronic low back pain, psychological evaluation, depression, generalized anxiety disorder, somatoform disorder, Pain Patient Profile (P3)

chopathology can significantly interfere with successful rehabilitation of the patients suffering with chronic low back pain (20). In addition, Gatchel (20) described that rehabilitation programs without an adequate mental health component may therefore be "doomed to failure." Further, it has been described that psychopathology may also increase pain intensity and disability, thus, serving to perpetuate pain related dysfunction $(21,22)$. Anxiety and depression also have been associated with magnification of medical symptoms, whereas emotional distress has been connected to physical symptoms by means of autonomic arousal, vigilance, and misinterpretation or somatic amplification $(1,23-25)$. Depression has been associated with less successful treatment outcomes $(26,27)$. The literature provides evidence that mood, fear, emotional state, and anxiety influence an individual's response to pain (2836). However, strong associations between psychometric scores and various aspects of behavior related chronic pain, abnormal psychosocial characteristics, do not prove the causal relationship between low back pain and psychological abnormalities (36-38).

Epker and Block (39) in a review of presurgical psychological screening and back pain patients concluded that it should be included in the medical diagnostic process of spine surgery candidates, especially when the major goal 
is pain reduction or when the surgeon recognizes the existence of psychosocial risk factors. Carragee (19) concluded that patients with discographic diagnosis of discogenic low back pain have poorer functional scores and very abnormal psychological scores. He further concluded that chronic moderately severe mechanical low back pain in healthy subjects was not associated with abnormal psychological scores or functional disability. Carragee (40) in the review of psychological screening in the surgical treatment of lumbar disc herniation, however, concluded that outcome after surgery for a herniated lumbar disc is strongly influenced by a number of pathologic factors (size and type of herniation and duration of illness). Further, he described that psychological screening seems to be most useful in those patients with lesser degrees of discopathologic findings, longer disability, and confounding economic issues. Dersh et al (1) concluded that a large body of research has consistently documented elevated rates of psychopathology in chronic spinal disorder patients, even though relationship between chronic spinal disorders and psychopathology is complex. However, Gatchel et al (11) failed to predict a patient's ability to successfully return to work in spite of high rates of axis I and axis II psychiatric disorders in a sample of 152 patients with chronic low back pain in an intensive 3-week rehabilitation program. In contrast, Burton et al (41) concluded that several factors, including a past diagnosis of substance abuse, a past and/or current diagnosis of an anxiety disorder and a variety of other demographic and psychosocial variables, were associated with lower return-towork rates 1-year after completion of the rehabilitation program. Thus, results are not only contradictory, but less than satisfactory. A considerable amount of research has been devoted to profiling the psychological and behavioral characteristics of chronic pain patients using numerous psychological instruments (41). Ideally, patient evaluation of psychological profile should be useful for classifying individual patients, determining treatment strategies, and predicting treatment response, apart from developing a better understanding of the psychological mechanisms mediating the pain experience. The clinical results of interventional procedures are often mediated by several factors in addition to physical illness, including the patient's emotional status, social environment, lifestyle, and incentive for treatment. Many of these factors have been shown to be predictive of poor surgical outcome (39). Ideally, psychologic evaluation is performed by a trained psychologist or a psychiatrist with an interview and utilization of self-report instruments. This requires identification of the patients requiring the services of a psychologist or psychiatrist and availability of psychiatrists and psychologists interested in pain management in the community, and finally feasibility rests on financial resources. A comprehensive psychological interview and evaluation are extensive and expensive, not covered by many insurers, resulting in practical problems for interventional pain physicians. Clinical trials have established the efficacy of antidepressant medications and specific psychotherapies for depressive psychiatric and primary care patients when care is provided by trained resource personnel or under standardized protocols (42-46). Olfson et al (46) in evaluating the recent advances in pharmacotherapy and recent advances in pharmacotherapy of depression compared transient outpatient treatment of depressive disorders in the United States in 1987 and 1997. They showed that there was a marked increase in the proportion of the population who received outpatient treatment for depression. Treatment became characterized by greater involvement of physicians, greater use of psychotropic medications, but fewer outpatient visits and less use of psychotherapy. Thus, evaluation of psychological problems in patients suffering with low back pain is performed more by nonpsychiatrists and nonpsychologists. However, comprehensive psychological evaluation still continues to be performed by mental health professionals including psychologists and psychiatrists. There are numerous self-report instruments or psychological tests providing standardized, reliable, and valid assessment of psychological variables that may influence pain perception and behavior. The Minnesota Multiphasic Personality Inventory (MMPI) and the Millon Clinical Multiaxial Inventory (MCMI) are considered as major psychological tests. Both the tests are long, and time consuming, and MMPI should be administered only under the supervision of a clinical psychologist. Thus, what a pain physician needs is an objective psychological test that can be easily administered by a nurse, that requires less than 15 minutes of patient's time, that can be computed, interpreted, and available to the physician within minutes, and that enjoys reasonable statistical reliability and validity based on national samples of patients in pain and national samples of community subjects. It also is important for the test to be inexpensive as pain physicians may not be reimbursed for psychological evaluation even though it adds to the complexity of medical decision making. Pain Patient Profile (P3) is a test which comes close to meeting all the requirements. The P3 was developed by Tollison and Langley (47) in 1993. The P3 is a clinically effective instrument for briefly assessing psychological characteristics that are known to effect pain perception and treatment response of patients in pain. The $\mathrm{P} 3$ consists of 34 items, each having three response options that collectively comprise four clinical sub scales which include somatization, 
depression, and anxiety. These are the three variables significant in patients suffering with chronic low back pain. An additional advantage of the P3 is that its intent is to compare the symptoms of an individual pain patient to the symptoms of the average pain patient. Thus, this test realizes that the average pain patient is significantly more depressed, anxious and preoccupied with somatic complaints than the average community subject and incorporates this knowledge into its assessment.

Thus far, most evaluations have focused on evaluation of psychological factors prior to either surgical intervention or functional rehabilitation in chronic low back pain patients, utilizing major psychological instruments and comprehensive evaluation. One study evaluating patients presenting to interventional pain management setting showed that generalized anxiety disorder was present in $40 \%$ of the patients vs $14 \%$ of the controls, major depression was present in $22 \%$ of the patients vs $24 \%$ of the controls, and somatization disorder was present in $26 \%$ of the patients vs $0 \%$ of the controls (13). However, this study included patients with a spectrum of pain problems Hence, this evaluation was undertaken to evaluate psychological status of patients suffering with chronic low back pain presenting to interventional pain management setting and compare those individuals with a control group without history of pain or psychopathology, utilizing a standardized simple psychological instrument, Pain Patient Profile (P3).

\section{METHODS}

This study was designed to evaluate 40 individuals without any type of pain or psychopathology (group I), control group; and 40 patients with chronic low back pain (Group II) in a private interventional pain management practice in a non-university setting. The control group was recruited from the non-pain patient population. Patients younger than 18 years or older than 90 years, those who had pain for less than six months, and those who were unable to undergo psychological evaluation and testing were excluded from the low back pain patient group. In the control group, if the patients suffered with any type of pain, chronic or acute, were diagnosed with psychopathology, were on any psychotherapeutic drugs, or receiving any type of psychological management were excluded. There was no renumeration for any of the participants. Forty consecutive patients with primary complaint of low back pain were who agreed to participate were included.

Patients in both groups, Group I, the control group, with no pain; and group II, chronic low back pain, were evalu- ated with Pain Patient Profile. P3 was administered to all participants in both groups.

Following the completion of the study, data were analyzed for various aspects of psychopathology. Data were recorded on a database using Microsoft $\AA$ Access $®$; the SPSS version 9.0 statistical package. Chi-squared statistic was used to test the significance difference between groups. Fischer's exact test was used wherever expected value was less than five. Student's t test was used to test mean difference between gender. Results were considered statistically significant if the $\mathrm{p}$ value was less than 0.05 .

\section{RESULTS}

The results showed no significant differences in patient characteristics of Group I and Group II.

Clinical syndromes included generalized anxiety disorder, somatoform disorder, major depression, bipolar manic depression, alcohol dependence, post traumatic stress, dysthymic disorder and drug dependence (Table 1). The results showed that significantly greater proportion of patients with chronic low back pain suffered with generalized anxiety disorder (20\%), somatization disorder (20\%), and depression $(30 \%)$.

\section{DISCUSSION}

Multiple psychological evaluations have been designed to evaluate a patient's personality, along with various other issues. However, the clinical relevance of personality has been proven to be of little use in management of chronic low back pain. In contrast to personality profiles, the role of various clinical syndromes in experience of pain is undeniable (13). Thus, it is clear that chronic low back pain is often associated and influenced by anxiety, depression, and somatization. Most psychological evaluations are performed by self-report instruments or psychological tests.

Table 1. Clinical syndromes in participants of the study

\begin{tabular}{lcc}
\hline & $\begin{array}{c}\text { Group I Group II low } \\
\text { control }\end{array}$ & $\begin{array}{c}\text { back pain } \\
\text { bepression }\end{array}$ \\
\hline Generalized anxiety disorder & $0 \%$ & $30 \% *$ \\
Somatization disorder & $0 \%$ & $20 \% *$ \\
\hline Indicates significant difference & & \\
\hline
\end{tabular}


The most commonly used self-report instruments in evaluation of chronic pain are Minnesota Multiphasic Personality Inventory (MMPI), Symptom Checklist-90 (SCL-90), or Millon Clinical Multiaxial Inventory (MCMI), Millon Behavorial Health Inventory (MBHI), Illness Behavior Questionnaire (IBQ), Beck's Depression Inventory (BDI), Hamilton Rating Scale for Depression, Zung Self-Rating Depression Scale, Zung self-rating anxiety scale, the Spielberger State-Trait Anxiety Inventory, Modified Somatic Perception Questionnaire (MSPQ), and pain patient profile P3 among others.

The Pain Patient Profile (P3) offers several advantages to pain professionals. Its format and content are simple, it can be administered in approximately 15 minutes as part of an initial clinical evaluation, and it can also be re-administered throughout the treatment to measure clinical progress; or it can serve as a pre- and post-treatment objective measure of clinical effectiveness. Thus, it can be administered by interventional pain practitioners or nurses in the practice with ease. The P3 has three clinical scales, which include depression, anxiety, and somatization, along with a validity index that assesses the probability of random responding, inadequate reading comprehension, and magnification of symptoms. The test realizes that average pain patient does have some symptoms of depression, anxiety, and somatization; and even patients with below-average scores may exhibit symptoms. Normative samples included a total of 497 subjects in cross-validating the 44item version of the P3. Often 497 patients, approximately half of the subjects were pain patients and the other half were community subjects. Pain patients scored significantly higher than community subjects on all three clinical scales. Specifically, the depression score for the average pain patient was nearly three standard deviations above the depression score for the average community subject, the average patient's anxiety score was two standard deviations above the average community subject score, and the average patient somatization score was almost four standard deviations above the average community subjects score. This information is crucial for the evaluator; since a particular patient may appear "average" compared to other pain patients on a clinical scale, he or she would appear considerably "above average" on that scale compared to the community subjects. Further, the test was shown to have test-retest reliability, internal consistency, intra-correlations of $\mathrm{P} 3$ scales and also correlation with the MMPI, correlating well in terms of depression scales, the MMPI hysterias scale with the P3 anxiety scale, and the MMPI hypochondriasis scale with the P3 somatization scale.
Polatin et al (9) in evaluating the relationship of psychopathology and chronic low back pain in 200 patients showed that depressive disorders accounted for $49 \%$ of current prevalence and $68 \%$ of lifetime prevalence in chronic low back pain patients, whereas anxiety disorders were present in $15 \%$ of the patients with substance abuse disorders in $19 \%$ of the patients. In addition, $51 \%$ met criteria for at least one personality disorder. Polatin et al (9) also showed that, even when category of somatoform pain disorder was excluded, $77 \%$ of patients met lifetime diagnostic criteria and $59 \%$ demonstrated current symptoms for at least one psychiatric diagnosis. The most common diagnoses in this study were major depressive disorder, substance abuse, and anxiety disorders. Kinney et al (48) found high rates of psychopathology in chronic low back pain group with higher rates of major depressive disorder, substance abuse, and personality disorders than the patients with acute low back pain. However, acute patients were also diagnosed with more anxiety disorders.

Apart from clinical disorders such as depression, generalized anxiety disorder and somatoform disorder, the influence of personality on pain experience has long interested clinicians working with individuals having chronic pain (49). Many of early theories of chronic pain also maintain that personality played an important role in the development and maintenance of chronic pain conditions $(15,16$, 49). However, in a prospective evaluation comparing the patients with chronic pain to general population, no significant differences were reported in personality patterns, path disorders or pathology (13). Lifetime and current rates of mental disorders in the general population were estimated to be $29 \%$ to $38 \%$, and $15 \%$ respectively (50-52). The presence of anxiety disorders in the US population has been reported to be $13 \%$ (53), whereas, depressive disorders have been reported in $10 \%$ of the US population age 18 and older with a major depressive disorder in $5 \%$ of the patients $(51,52)$.

The present study sought to compare the psychological status of patients suffering with chronic low back pain with individuals without pain. A significantly greater proportion of patients with chronic low back pain presented with generalized anxiety disorder, somatoform disorder, and major depression. This study showed that $30 \%$ of the patients suffered with depression, $20 \%$ of the patients with generalized anxiety disorder, and $20 \%$ of the patients with in Group II, with 5\% of the control group with depression and $0 \%$ with generalized anxiety disorder or somatization in the control group. Incidence of generalized anxiety dis- 
order in $20 \%$ of the patients in the chronic low back pain group is similar to previous studies as Polatin et al (9) reported anxiety disorders to be present in $15 \%$ of the patients, but differs from Manchikanti et al (13) reporting generalized anxiety disorder in $40 \%$ of the patients with chronic pain and $14 \%$ in control group. The $0 \%$ incidence of anxiety disorder in the present study in control group differed to the incidence of $13 \%$ population in the age group of 18 to 54 in US population (53). Asmundson et al (54) also showed that only $18 \%$ of the patients with chronic musculoskeletal pain were diagnosed with a current anxiety disorder, results similar to the present study. Atkinson et al (55) however, comparing patients with low back pain to a matched sample of pain-free men found that the chronic pain groups had significantly higher lifetime prevalence rates of major anxiety disorder of $31 \%$ versus $14 \%$ with results differing from the present study.

Depressive disorder was shown to be present in $30 \%$ of the participants in Group II, whereas it was present in 5\% of individuals in Group I. Statistics show that approximately $10 \%$ of the US population age 18 and older have a depressive disorder (50-52). Polatin et al (9) showed that major depressive disorder was the most common of all psychopathological conditions with current prevalence of $45 \%$ and lifetime prevalence of $64 \%$. Manchikanti et al (13) showed incidence of major depression in $22 \%$ of the patients, whereas Magni et al (7) showed incidence of depression as $18 \%$. Fishbain et al (56) also showed depression to be present in $30 \%$ of the patients. Overall, it appears that our results, while in correlation with some studies, differed with some others.

Somatization disorder was shown to be present in $20 \%$ of the patients in this study. Somatization disorder is not only a complex disorder, but also a complicated and controversial psychiatric diagnosis. Katon et al (3) and Manchikanti et al (13) diagnosed somatization disorder in $16 \%$ and $26 \%$ of patients respectively.

Carragee et al (57) postulated that somatization can produce false-positive results in patients without back pain, with provocative discography, however, they utilized Modified Somatic Perception Questionnaire (MSPQ) which evaluates somatic perception rather than somatization disorder or somatoform disorder. In contrast, Manchikanti et al (58) evaluated the role of psychological factors, including somatization into two distinct groups of patients with or without somatization in provocative discography and showed there was no difference in the diagnostic yield of the results. In addition, Manchikanti et al (59) also showed lack of influence of somatization on the diagnosis of facet joint pain utilizing comparative local anesthetic blocks. Further, Manchikanti et al $(58,59)$ showed lack of influence of anxiety disorders, depressive disorders, as well as somatization disorder on the diagnostic capability either with provocative discography, or comparative local anesthetic blocks in the diagnosis of discogenic pain or facet joint pain.

Our data supports the association between chronic low back pain and psychopathology with clinical syndromes. This emphasizes the fact that in a significant number of patients, there is a physical problem associated with emotional issue.

While there is no data showing the psychological predictors to outcome of interventional pain procedures, there has been a growing body of evidence showing the influence of physical, psychological and psychosocial factors on outcome of lumbar surgery $(19,39,40)$. The soundness of psychometric evaluation routinely presented in the literature, has been questioned (60). Personality disorders are lifelong pervasive stable traits, and clinical utility of this personality evaluation is very narrow as it is an extremely time consuming, expensive evaluation with low rate of satisfactory completion by patients (60). Anxiety disorders, depressive disorders, and somatoform disorders have been evaluated with numerous tests yielding highly variable results. Multiple reports also have shown (12, 61-65) improvement in psychological status following appropriate diagnosis and treatment of the painful condition.

\section{CONCLUSION}

In conclusion, a significant proportion of patients in chronic low back pain group presented with depression $(30 \%)$, generalized anxiety disorder $(20 \%)$, and somatization $(20 \%)$. Hence, it may be prudent to evaluate most, if not all patients with chronic low back pain presenting to interventional pain management for psychopathology.

\section{REFERENCES}

1. Dersh J, Gatchel RJ, Polatin P. Chronic spinal disorders and psychopathology: research findings and theoretical considerations. Spine 2001; 1:88-94.

2. Fishbain DA, Goldberg M, Steele R et al. Compensation and non-compensation chronic pain patients compared for DSM-III operational diagnoses. Pain 1988; 32:197-206.

3. Manchikanti L, Fellows B, Singh V. Understanding psychological aspects of chronic pain in interventional 
pain management. Pain Physician 2002; 5:57-82.

4. Krishnan K, France R, Pelton S. Chronic pain and depression. I: Classification of depression in chronic low back pain patients. Pain 1985; 22:279-287.

5. Krishnan K, France R, Pelton S. Chronic pain and depression. II: Symptoms of anxiety in chronic low back pain patients and their relationship to subtypes of depression. Pain 1985; 22:289-294.

6. Large RG. DSM-III diagnoses in chronic pain: Confusion or clarity? J Nerve Mental Disabil Assess 1986; 17:295-303.

7. Magni G, Caldieron C, Rigatti-Luchini S et al. Chronic musculoskeletal pain and depressive symptoms in the general population: An analysis of the first national and nutrition examination survey data. Pain 1990; 43:299-307.

8. Reich J, Tupin J, Abramowitz S. Psychiatric diagnosis of chronic pain patients. Am J Psychiat 1983; 142:1495-1498.

9. Polatin PB, Kinney RK, Gatchel RJ et al. Psychiatric illness and chronic low back pain: The mind and the spine -which goes first? Spine 1993; 18:66-71.

10. Gatchel RJ, Polatin PB, Mayer TG. The dominant role of psychosocial risk factors in the development of chronic low back pain disability. Spine 1995; 20:27022709.

11. Gatchel RJ, Polatin PB, Mayer TG et al. Psychopathology and the rehabilitation of patients with chronic low back pain disability. Arch Phys Med Rehab 1994; 75:666-670.

12. Vittengl JR, Clark LA, Owen-Salter E et al. Diagnostic change and personality stability following functional restoration treatment in chronic low back pain patients. Psychol Assessment 1999; 6:79-91.

13. Manchikanti L, Fellows B, Pampati V et al. Comparison of psychological status of chronic pain patient and the general population. Pain Physician 2002; 5:4048 .

14. Kramlinger KG, Swanson DW, Maruta T. Are patients with chronic pain depressed? Am J Psychiatry 1983; 140:747-749.

15. Weisberg JN, Keefe FJ. Personality disorders in the chronic pain population: Basic concepts, empirical findings, and clinical implications. Pain Forum 1997; 6:1-9.

16. Manchikanti, L, Fellows, B, Singh, V. Understanding psychological aspects of chronic pain in interventional pain management. Pain Physician 2002; 5:57-82.

17. Bigos S, Battie M, Spengler D et al. A prospective study of work perceptions and psychosocial factors affecting the report of back injury. Spine 1991; 16:16.

18. Wiltse L, Rocchio P. Pre-operative psychological tests as predictors of success of chemonucleolysis in the treatment of low back pain. J Bone Joint Surg 1975:57:478-483.
19. Carragee EJ. Psychological and functional profiles in select subjects with low back pain. The Spine Journal 2001; 1:198-204.

20. Gatchel RJ. Psychological disorders and chronic pain: Cause-and-effect relationships. In Psychological approaches to pain management: A practitioners handbook. Gatchel RJ, Turk DC (eds). Guilford Publications, New York, 1996:33-52.

21. Hensing G, Spak F. Psychiatric disorders as a factor in sick leave due to other diagnoses: a general population-based study. Br J Psychiat 1998; 172:250-256.

22. Holzberg AD, Robinson ME, Geisser ME. The effects of depression and chronic pain on psychosocial and physical functioning. Clin J Pain 1996; 12:118125 .

23. Katon WJ. The impact of major depression on chronic medical illness. Gen Hosp Psychiat 1996; 18:215-219.

24. Sullivan M, Katon W. Somatization: the path between distress and somatic symptoms. Am Pain Soc J 1993; 2:141-149.

25. Barsky AJ, Klerman GL. Overview: hypochondriasis, bodily complaints, and somatic styles. Am J Psychiat 1983; 140:273-283.

26. Burchiel KJ, Anderson VC, Wilson BJ. Prognostic factors of spinal cord stimulation for chronic back and leg pain. Neurosurgery 1995; 36:1101-1111.

27. Burns JW, Johsnon BJ, Mahoney N et al. Cognitive and psychical capacity process variables predict longterm outcome after treatment of chronic pain. J Clin Cons Psycho 1998; 66:434-439.

28. Cornwal A, Doncleri DC. The effect of experimentally induced anxiety on the experience of pressure pain. Pain 1988; 35:105-113.

29. Kremer E, Atkinson JH, Fagnelzi RN. Measurement of pain: patient preference does not confound pain measurement. Pain 1981; 51:281-287.

30. Staats PS, Staats A, Hekmat H. The additive impact of anxiety and a placebo on pain. Pain Medicine 2001; 2:267-279.

31. Zelman DC, Howland EW, Nichols SN et al. The effects of induced mood on laboratory pain. Pain 1991; 46:105-111.

32. McCraken LM, Zayfert C, Gross RT. The Pain Anxiety Symptoms Scale: Development and validation of a scale to measure fear of pain. Pain 1992; 50:67-73. Pfingsten M, Leibing E, Harter W et al. Fear-avoidance behavior and anticipation of pain in patients with chronic low back pain: A randomized controlled study. Pain Medicine 2001; 2:259-266.

34. Waddell G, Newton M, Henderson I et al. A fearavoidance beliefs questionnaire (FABQ) and the role of fear-avoidance beliefs in chronic low-back pain and disability. Pain 1993; 52:157-168.

35. Philips HC. Avoidance behaviour and its role in sustaining chronic pain. Behav Res Ther 1987; 25:273279 
36. Main CJ, Waddell G. Psychiatric distress. In Waddell $\mathrm{G}$ (ed). The back pain revolution. Churchill Livingstone, Philadelphia, 1998, pp 173-186.

37. Magni G. Chronic low-back pain and depression: An epidemiologic survey. Acta Psychiatr Scand 1984; 70:614-617.

38. Heliovaara M. Risk factors for low back pain and sciatica. Ann Med 1989; 21:257-264.

39. Epker J, Block A. Presurgical psychological screening in back pain patients: A review. Clin J Pain 2001; 17:200-205.

40. Carraggee EJ. Psychological screening in the surgical treatment of lumbar disc herniation. Clin J Pain 2001; 17:215-219.

41. Burton K, Polatin PB, Gatchel RJ. Psychosocial factors and the rehabilitation of patients with chronic work-related upper extremity disorders. J Occup Rehabil 1997; 7:139-153.

42. Wells KB, Sherbourne C, Shoenbaum M et al. Impact of disseminating quality improvement programs for depression in managed primary care. A randomized controlled trial. JAMA 2000; 283;212-220.

43. Depression Guidelines Panel. Depression in Primary Care, I: Detection and Diagnosis. Rockville, MD. US Dept of Health and Human Services, 1993. US Public Health Service, Agency for Health Care Policy and Research publication 93-0550.

44. Schulberg HC, Block MR, Madonia MJ et al. Treating major depression in primary care practice: 8 -month clinical outcomes. Arch Gen Psychiatry 1996; 53:913919.

45. Malt UF, Robak OH, Madsbu H-P et al. The Norwegian Naturalistic Treatment Study of Depression in General Practice (NORDEP)-I: Randomized double blind study. BMJ 1999; 318:1180-1184.

46. Olfson M, Marcus SC, Druss B et al. National trends in the outpatient treatment of depression. JAMA 2002; 287:203-209.

47. Tollison CD, Langley JC. Pain Patient Profile (P-3) Manual. National Computer Systems, Minneapolis, 1995.

48. Kinney RK, Gatchel RJ, Polatin PB et al. Prevalence of psychopathology in acute and chronic low back pain patients. J Occup Rehab 1993; 3:95-103.

49. Woodforde JM, Merskey H. Personality traits of patients with chronic pain. J Psychosom Res 1972; 16:167-172.

50. Regier DA, Boyd JH, Burke JD et al. One-month prevalence of mental disorders in the United States. Arch Gen Psychiat 1988; 45:977-986.

51. Regier DA, Narrow WE, Rae DS et al. The de facto mental and addictive disorders service system. Epidemiologic Catchment Area prospective 1-year prevalence rates of disorders and services. Arch Gen Psychiatry 1993; 50:85-94.

52. Narrow WE. One-year prevalence of mental disor- ders, excluding substance use disorders, in the U.S.: NIMH ECA prospective data. Population estimates based on U.S. Census estimated residential population age 18 and over on July 1, 1998.

53. Narrow WE, Rae DS, Regier DA. NIMH epidemiology note: Prevalence of anxiety disorders. One-year prevalence best estimates calculated from ECA and NCS data. Population estimates based on U.S. Census estimated residential population age 18 to 54 on July 1, 1998.

54. Asmundson GJ, Jacobson SJ, Allerdings MD et al. Social phobia in disabled workers with chronic musculoskeletal pain. Behav Res Ther 1996; 34:939-943.

55. Atkinson JH, Slater MA, Patterson TL et al. Prevalence, onset, and risk of psychiatric disorders in men with chronic low back pain: A controlled study. Pain 1991; 45:111-121.

56. Fishbain DA, Cutler R, Rosomoff HL et al. Chronic pain associated depression: Antecedent or consequence of chronic pain? A review. Clin J Pain 1997; 13:116137.

57. Carragee EJ, Tanner CM, Khurana S et al. The rates of false-positive lumbar discography in select patients without low back symptoms. Spine 2000; 25:13731381.

58. Manchikanti L, Singh V, Pampati VS et al. Provocative discography in low back pain patients with or without somatization disorder: A randomized, prospective evaluation. Pain Physician 2001; 4:227-239.

59. Manchikanti L, Pampati V, Fellows B et al. Influence of psychological factors on the ability to diagnose chronic low back pain of facet joint origin. Pain Physician 2001; 4:349-357.

60. Trief PM, Grant W, Fredrickon B. A prospective study of psychological predictors of lumbar surgery outcome. Spine 2000; 25:2616-2621.

61. Wallis BJ, Lord SM, Bogduk N. Resolution of psychological distress of whiplash patients following treatment by radiofrequency neurotomy: A randomized, double-blind placebo-controlled trial. Pain 1997; 73:15-22.

62. Manchikanti L, Pampati V, Bakhit C et al. Effectiveness of lumbar facet joint nerve blocks in chronic low back pain: A randomized clinical trial. Pain Physician 2001; 4:101-117.

63. Manchikanti L, Pampati V, Fellows B et al. Role of one day epidural adhesiolysis in management of chronic low back pain: A randomized clinical trial. Pain Physician 2001; 4:153-166.

64. Manchikanti L, Pampati VS, Rivera J et al. Caudal epidural injections with Sarapin or steroids in chronic low back pain. Pain Physician 2001; 4:322-335.

65. Manchikanti L, Singh V, Rivera J et al. Effectiveness of caudal epidural injections in discogram positive and negative chronic low back pain. Pain Physician 2002; 5:18-29. 